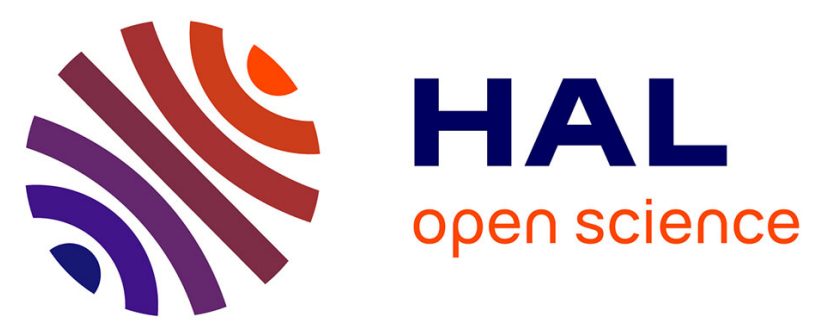

\title{
From metabolic connectivity to molecular connectivity: application to dopaminergic pathways
}

Antoine Verger, Tatiana Horowitz, Mohammad Chawki, Alexandre Eusebio, Manon Bordonne, Jean-Philippe Azulay, Nadine Girard, Eric Guedj

\section{To cite this version:}

Antoine Verger, Tatiana Horowitz, Mohammad Chawki, Alexandre Eusebio, Manon Bordonne, et al.. From metabolic connectivity to molecular connectivity: application to dopaminergic pathways. European Journal of Nuclear Medicine and Molecular Imaging, 2020, 47 (2), pp.413-424. 10.1007/s00259019-04574-3 . hal-02479675

\section{HAL Id: hal-02479675 \\ https://hal.science/hal-02479675}

Submitted on 21 Apr 2020

HAL is a multi-disciplinary open access archive for the deposit and dissemination of scientific research documents, whether they are published or not. The documents may come from teaching and research institutions in France or abroad, or from public or private research centers.
L'archive ouverte pluridisciplinaire HAL, est destinée au dépôt et à la diffusion de documents scientifiques de niveau recherche, publiés ou non, émanant des établissements d'enseignement et de recherche français ou étrangers, des laboratoires publics ou privés. 


\section{From metabolic connectivity to molecular connectivity: application to}

\section{dopaminergic pathways}

Antoine Verger ${ }^{1,2}$; Tatiana Horowitz ${ }^{3,4,5}$; Mohammad B. Chawki ${ }^{1}$; Alexandre Eusebio ${ }^{6,7}$;

Manon Bordonne ${ }^{1}$; Jean-Philippe Azulay ${ }^{6,7}$; Nadine Girard ${ }^{8,9}$; Eric Guedj ${ }^{3,4,5}$.

${ }^{1}$ Department of Nuclear Medicine \& Nancyclotep Imaging platform, CHRU Nancy, F-54000 Nancy, France

${ }^{2}$ Université de Lorraine, INSERM, IADI, F-54000 Nancy, France

${ }^{3}$ Department of Nuclear Medicine, CHU Timone, AP-HM, Marseille, France

${ }^{4}$ Aix Marseille Université, CNRS, Centrale Marseille, Institut Fresnel, Marseille, France

${ }^{5}$ CERIMED, Aix-Marseille Université, Marseille, France

${ }^{6}$ Department of Neurology and Movement Disorders, CHU Timone, AP-HM, Marseille, France

${ }^{7}$ Aix Marseille Université, CNRS, INT, Inst Neurosci Timone, Marseille, France

${ }^{8}$ Department of Neuroradiology, CHU Timone, AP-HM, Marseille, France

${ }^{9}$ Aix-Marseille Université, CNRS, CRMBM, Marseille, France.

\section{Original Article}

Word count: 4,453

\section{Address for correspondence:}

Eric Guedj, M.D., Ph.D.

eric.guedj@ap-hm.fr

Service Central de Biophysique et Médecine Nucléaire, Hôpital de la Timone, 264 rue Saint Pierre, 13005 Marseille, France.

Tel: +33-491385558; Fax: +33-491384769

Running title: Molecular connectivity for dopaminergic pathways

Keywords: Connectivity; metabolism; molecular imaging; neurotransmission; dopaminergic pathways; PET; SPECT 


\begin{abstract}
This study aims to reveal the feasibility and potential of molecular connectivity based on neurotransmission in comparison to the metabolic connectivity with an application to dopaminergic pathways. For this purpose, we propose to compare the neurotransmission connectivity findings using ${ }^{123}$ I-FP-CIT SPECT and ${ }^{18}$ F-FDOPA PET to the metabolic connectivity findings using ${ }^{18}$ F-FDG PET.

Methods: ${ }^{18}$ F-FDG PET and ${ }^{123}$ I-FP-CIT SPECT images from 47 subjects and ${ }^{18}$ F-FDOPA PET images from 177 subjects, who had no neurological or psychiatric disorders, were studied. Interregional correlation analyses were performed at the group level to determine the midbrain's connectivity via glucose metabolic rate using ${ }^{18}$ F-FDG PET, and via dopaminergic binding potential using ${ }^{123}$ I-FP-CIT SPECT and ${ }^{18}$ F-FDOPA PET. SPM-T maps of each radiotracer were generated, and masks used to highlight the significant differences obtained among the imaging modalities and targets.
\end{abstract}

Results: The three dopaminergic pathways (i.e. nigrostriatal, mesolimbic and mesocortical) were identified by ${ }^{18}$ F-FDG PET (1,599 voxels, with a T-max value of 12.6$),{ }^{123}$ I-FP-CIT SPECT (1,120 voxels, with T- max value of 5.1), and ${ }^{18}$ F-FDOPA PET (6,054 voxels, with Tmax value of 11.7) for a T-voxel threshold of 5.10, 2.80 and 5.10, respectively. Using the same T-voxel threshold of 5.10, ${ }^{18} \mathrm{~F}$-FDOPA PET showed more specific findings than ${ }^{18} \mathrm{~F}$ FDG PET with less voxels identified outside these pathways (-9,323 voxels), whereas no significant voxels were obtained with ${ }^{123}$ I-FP-CIT SPECT at this threshold.

Conclusion: The present study illustrates the feasibility and interest in using molecular connectivity with ${ }^{18}$ F-FDOPA PET for dopaminergic pathways. Such analyses could be applied to specific diseases involving the dopaminergic system. 


\section{Introduction}

The number of studies assessing metabolic connectivity with ${ }^{18} \mathrm{~F}-\mathrm{FDG}$ positron emission tomography (PET) is impressively increasing [1-4]. This connectivity approach rests on the fact that different brain areas are metabolically connected when they share similar spatial variance in radiotracer uptake [1]. In particular, this approach has been applied to study neurodegenerative disorders, including movement disorders [5,6], especially with the method of interregional correlation analysis (IRCA) developed by Lee et al. [7,8]. It allows to study connectivity seeding a cluster of voxels of interest. Compared to functional magnetic resonance imaging (fMRI), metabolic connectivity provides better signal-to-noise ratios, variance concentration and out-of-sample replication. This original approach could be extended to other targets by disclosing associations based on molecular information from single photon emission computed tomography (SPECT) and PET imaging techniques [9-13]. The advantage of using such an analysis is to switch from a global metabolic point of view to obtaining more specific molecular information, for example on the various targets of neurotransmission.

Among these targets, much interest has been directed toward the dopaminergic system since the discovery of dopamine as a neurotransmitter in the 1960s [14] and later because of its involvement in movement disorders, executive functions, learning, reward, and motivation [15-17]. The mesotelencephalic dopamine system consists of three dopaminergic pathways arising from the midbrain: the nigrostriatal, mesolimbic and mesocortical pathways, with the latter two referred to as the mesocorticolimbic system [18-20]. In more details, neuroanatomic research has led to a precise description of these pathways generally in the mammal brain but also in the human brain [18-25]: the dopaminergic neurons from the substantia nigra $(\mathrm{SN})$ project through the nigrostriatal pathway mainly to the caudate and the putamen, and the dopaminergic neurons from the ventral tegmental area (VTA) project 
mainly to the frontal cortex and the limbic system forming the mesocortical and mesolimbic pathways, respectively.

The aim of the current study is to reveal the feasibility and potential of molecular connectivity based on neurotransmission in comparison to the metabolic connectivity with an application to these 3 dopaminergic pathways. The midbrain's connectivity and related dopaminergic pathways were analyzed in cohorts of subjects without neurological or psychiatric disorders. This study compares the connectivity findings of three distinct radiotracers: i.) ${ }^{18}$ F-FDG, currently used to study glycolytic metabolism PET connectivity [26], ii.) ${ }^{123}$ I-FP-CIT, for the SPECT evaluation of the dopamine transporter (DaT) [27], and iii.) ${ }^{18} \mathrm{~F}-\mathrm{FDOPA}$, for the PET evaluation of Dopa decarboxylase [28]. We hypothesize that connectivity based on neurotransmission will better reveal the dopaminergic pathways than those based on glycolytic metabolism. 


\section{Methods}

\section{Population}

Regarding the ${ }^{123}$ I-FP-CIT SPECT and ${ }^{18}$ F-FDG PET imaging, images from 55 healthy subjects who had both PET and SPECT scans, and had a brain MRI interpreted as normal, were selected for this study [27]. The final population encompassed 47 subjects because of secondary exclusions owing to misregistration errors (described below). These subjects had given their written informed consent, which was approved by the local Ethics Committee (Sud-Méditerranée II) according to the Helsinki Declaration (clinical trial registration number: NCT00484523). The patients included in this study had no history of any neurological or psychiatric disorder nor any medication known to affect the brain, and in particular the dopaminergic system. This population included 28 women $(60 \%)$, with a mean \pm SD age of $49.4 \pm 16.7$ years (range $21-78$ years).

Regarding the ${ }^{18}$ F-FDOPA PET imaging, brain images from the whole-body acquisition of 177 patients referred for a known or suspected neuroendocrine tumor from a previous study were selected [29]. All patients were informed that their medical data would be rendered anonymous and used for scientific purposes, in accordance with the Helsinki Declaration. This study was approved on June 27, 2017 by the local institutional review board (CHRU Nancy, France) and the Ethics Committee (Comité pour la Protection des Personnes Est III). The patient selection for the analysis was performed with the same criteria as those reported for ${ }^{123}$ I-FP-CIT SPECT and ${ }^{18}$ F-FDG PET imaging. In addition, no carbidopa or any other enzyme inhibitor premedication likely to influence striatal and extrastriatal uptake was given before the examination [30]. This population included 105 women $(59 \%)$, with a mean \pm SD age of $59.2 \pm 14.2$ years (range $21-85$ years). 
Figure 1 depicts a flowchart resuming subjects' selection and image processing for ${ }^{18}$ F-FDG PET, ${ }^{123}$ I-FP-CIT SPECT and ${ }^{18}$ F-FDOPA PET.

\section{${ }^{18}$ F-FDG PET imaging and postreconstruction processes}

${ }^{18}$ F-FDG PET was performed using an integrated PET/CT camera (Discovery ST, General Electric Healthcare, Waukesha, WI) with an axial resolution of $6.2 \mathrm{~mm}$ allowing 47 contiguous transverse sections of the brain of $3.27 \mathrm{~mm}$ thickness, in patients fasting for at least 6 hours. ${ }^{18} \mathrm{~F}$-FDG $(150 \mathrm{MBq})$ was injected intravenously while the subjects were awake, in a resting state, with eyes closed in a quiet environment. Image acquisition started $30 \mathrm{~min}$ after injection and ended 15 min later. Images were reconstructed using the OSEM algorithm with 5 iterations and 32 subsets and corrected for attenuation using a CT transmission scan [31]. For spatial normalization, as also performed for the 123I-FP-CIT SPECT images (see below), the ${ }^{18}$ F-FDG PET images of each subject were initially coregistered to corresponding T1-MPRAGE MR images using the coregistration algorithm included in the SPM12 package (Wellcome Department of Imaging Neuroscience, Institute of Neurology, University College London, UK; run in MATLAB®; MathWorks Inc., Sherborn, MA). After this step, the MR images of the subjects were normalized to the Montreal Neurological Institute (MNI) MRI template, also using the algorithm provided with SPM12, and the resulting deformation field was applied to the PET scans with resulting images of $2 \times 2 \times 2 \mathrm{~mm} 3$ voxel size. All the normalized PET scans were visually checked. Then, a smoothing Gaussian filter was subsequently applied $(\mathrm{FWHM}=8 \mathrm{~mm})$.

${ }^{123}$ I-FP-CIT SPECT imaging and postreconstruction processes 
The same healthy subjects who had a ${ }^{18}$ F-FDG PET scan also underwent ${ }^{123}$ I-FP-CIT SPECT imaging. For this purpose, they received $148 \mathrm{MBq}$ of ${ }^{123}$ I-FP-CIT intravenously as a slow bolus over approximately 20 seconds followed by saline to flush the intravenous line after blocking thyroid uptake with $600 \mathrm{mg}$ of sodium perchlorate orally administered $30 \mathrm{~min}$ before tracer administration. Data acquisition started 4 hours after tracer administration and lasted for 35 min. All scans were performed with the same dual-detector gamma camera (ECAM, Siemens, Erlangen, Germany) equipped with fan beam collimators. The imaging data were reconstructed by standard filtered back-projection (Butterworth filter of order 4 with a cutoff frequency of $0.4 \mathrm{~cm}^{-1}$ ) [27]. Approach for spatial normalization was similar to those applied to the ${ }^{18}$ F-FDG PET images, using the corresponding T1-MPRAGE MR image of each patient for coregistration. All the normalized scans were visually checked, and misregistered scans were secondarily excluded from the analysis (data from 8 of the 55 healthy subjects). Thus, 47 subjects were finally selected for ${ }^{123}$ I-FP-CIT SPECT (and ${ }^{18}$ F-FDG PET) analysis with resulting images of through a $2 \times 2 \times 2 \mathrm{~mm} 3$ voxel size. Then, SPECT images were smoothed with a 3-dimensional Gaussian filter (FWHM $=8 \mathrm{~mm}$ ). Parametric images were obtained by normalizing all voxel intensities through a ratio with mean voxel activities from an occipital cortical reference area provided by PickAtlas (https://www.nitrc.org/projects/wfu_pickatlas/), in accordance with the semiquantitative analysis currently recommended for ${ }^{123}$ I-FP-CIT SPECT interpretation [32]. This reference area was extracted from the spatially normalized SPECT images using Marsbar software (http://marsbar.sourceforge.net/). Binding potential images were subsequently obtained at the voxel level by subtracting 1 from the previous parametric images [27].

\footnotetext{
${ }^{18}$ F-FDOPA PET imaging and postreconstruction processes
} 
${ }^{18}$ F-FDOPA PET/CT recordings were obtained on a Biograph hybrid system consisting of a six-detector CT for attenuation correction and anatomic localization (Biograph 6 True Point, Siemens). The whole-body PET/CT protocol was initiated 60 min after injection of $4 \mathrm{MBq} / \mathrm{kg}$ of ${ }^{18} \mathrm{~F}-\mathrm{FDOPA}$, in patients fasting for at least 4 hours [28,33]. Brain acquisitions of $210 \mathrm{sec}$ for subjects with $<100 \mathrm{~kg}$ of body weight and of $240 \mathrm{sec}$ for those with $>100 \mathrm{~kg}$, started approximately 90 min after the radiotracer injection.

The PET images were reconstructed with an iterative OSEM method (3 iterations and 8 subsets) and a 5-mm Gaussian postfilter, and the images were displayed through $2.8 \times 2.8 \times$ $2.8 \mathrm{~mm}^{3}$ voxels after an attenuation correction using a CT transmission scan. All sets of ${ }^{18} \mathrm{~F}-$ FDOPA PET images were spatially normalized using an adaptive template [29] through a $2 \times 2 \times 2 \mathrm{~mm}^{3}$ voxel size and were further smoothed with a Gaussian filter (FWHM $=8 \mathrm{~mm}$ ). The binding potential images were obtained by normalizing all voxel intensities through a ratio with mean voxel activities from an occipital cortical reference area, and calculated in a similar manner as described above for ${ }^{123}$ I-FP-CIT SPECT images.

\section{SPM analysis}

A voxel-by-voxel IRCA study design was employed using SPM12 (Wellcome Department of Imaging Neuroscience, Institute of Neurology, University College London, UK; run in MATLAB®; MathWorks Inc., Sherborn, MA). Regions of interest (ROIs) and masks derived from PickAtlas (https://www.nitrc.org/projects/wfu_pickatlas/) using the Automated Anatomical Labeling (AAL) atlas [34], and ROIs values were individually extracted with Marsbar software (http://marsbar.sourceforge.net/).

IRCA was applied to study connectivity of the midbrain [7]. Indeed, SPECT and PET systems provide limited spatial resolution, and the $\mathrm{SN}$ and the VTA, which dominating the mesotelencephalic dopamine system, belong to the midbrain. These analyses were directly 
conducted on ${ }^{123}$ I-FP-CIT SPECT and ${ }^{18}$ F-FDOPA PET parametric images expressed as binding potential. For ${ }^{18}$ F-FDG PET images, proportional scaling was applied to correct for individual variation in brain metabolism.

All the SPM (T) maps here presented are limited to gray-matter with age and sex as covariates. A dedicated inclusive gray-matter mask has thus been applied to exclude voxels corresponding to white-matter and cerebrospinal fluid. Furthermore, to limit falsely increased correlations due to correlated noise in areas with nonspecific radiotracer uptake, normalized values of centrum semi-ovale were also used as covariates for ${ }^{123}$ I-FP-CIT SPECT and ${ }^{18} \mathrm{~F}$ FDOPA PET parametric images, as previously suggested [10].

For ${ }^{18}$ F-FDG PET imaging, a threshold of p-voxel $<0.05$ corrected for multiple comparisons using family-wise error (FWE) method was applied; it corresponded to a T-voxel threshold of 5.10. A similar T-score map was applied for the ${ }^{123}$ I-FP-CIT SPECT and ${ }^{18}$ F-FDOPA PET imaging data. For the ${ }^{123}$ I-FP-CIT SPECT imaging, no significant results were obtained at this threshold, which led to the use of a less restrictive statistical value with a p-voxel $<0.05$ corrected for multiple comparison using false discovery rate (FDR); it corresponded to a Tvoxel threshold of 2.80. All these T-voxel thresholds have been determined at the whole brain level. A correction for cluster volume has also been applied to avoid type II errors, as recommended [35]. This correction was based on random field theory with a threshold of $\mathrm{k}$ voxels expected by cluster provided by SPM. These thresholds were of 20, 50 and 20 voxels for ${ }^{18}$ F-FDG PET, ${ }^{123}$ I-FP-CIT SPECT and ${ }^{18}$ F-FDOPA PET, respectively.

Clusters belonging to dopaminergic pathways were secondarily identified using three specific masks, one for each dopaminergic system as follow : i) the nigrostriatal pathway included the bilateral caudates, putamens and globus pallidus [22,24,36], ii) the mesolimbic pathway included the bilateral amygdalae, hippocampus, parahippocampus and the whole cingulate, and iii) the mesocortical pathway included bilateral prefrontal mesial, dorsolateral and 
orbitofrontal areas $[16,17,19,23]$. Because these issues are still debated [37-39], the possible dopaminergic innervations of the motor cortex, insula and thalamus were not considered in the framework of the mesotelencephalic system in the current article. Finally, findings obtained with 18F-FDG PET and not with 18F-FDopa PET (and vice versa) have been highlighted at the statistical threshold of 5.10. As a reminder, no significant results were obtained at this statistical threshold for ${ }^{123}$ I-FP-CIT imaging. For this purpose, exclusive mask corresponding to the SPM-T map of midbrain connectivity of the other radiopharmaceutical has been applied to neutralize common results obtained with the two targets (exclusive mask of ${ }^{18}$ F-FDG PET findings for ${ }^{18}$ F-FDopa PET analysis, and vice versa).

The precise identification of each structure located by its MNI coordinates, its respective volume, and T-max intensity were extracted by using the report provided by the SPM xjView toolbox (http://www.alivelearn.net/xjview).

\section{Results}

The results of midbrain connectivity for the ${ }^{18}$ F-FDG PET imaging are presented in Table 1 and Figure 2 with a T-voxel threshold value of 5.10 (p-voxel $<0.05$, corrected for multiple comparison with FWE method, and with a k cluster size threshold of 20 voxels). A total volume of 1,599 voxels was related to the 3 dopaminergic pathways: 409 voxels in the nigrostriatal pathway ( $T_{\max }$ at 9.6 with MNI coordinates $\left.x=16 ; y=-2 ; z=-6\right), 893$ voxels in the mesolimbic pathway ( $T_{\max }$ at 12.6 with MNI coordinates $\left.x=16 ; y=-6 ; z=-14\right)$, and 297 voxels in the mesocortical pathway $\left(\mathrm{T}_{\max }\right.$ at 7.1 with MNI coordinates $\left.\mathrm{x}=-42 ; \mathrm{y}=16 ; \mathrm{z}=-6\right)$. On the other hand, 16,412 voxels were found outside these 3 dopaminergic pathways, mainly in motor cortex and cerebellum, corresponding to $89 \%$ of the total volume of significant voxels.

The results of midbrain connectivity for the ${ }^{123}$ I-FP-CIT SPECT imaging are presented in Table 2 and Figure 3 with a less restrictive T-voxel threshold value of 2.80 (p-voxel<0.05, 
corrected for multiple comparison with FDR method, and with a k cluster size threshold of 50 voxels). There was indeed no significant results for the initial T-voxel threshold value of 5.10 after correction for the cluster size. The 3 dopaminergic pathways were highlighted through a total of 1,120 significant voxels. In details, the nigrostriatal and mesolimbic pathways were well defined (654 voxels, $\mathrm{T}_{\max }$ at 5.1 with MNI coordinates $\mathrm{x}=-22 ; \mathrm{y}=0 ; \mathrm{z}=-4$, and 415 voxels, $\mathrm{T}_{\max }$ at 5.0 with MNI coordinates $\mathrm{x}=20 ; \mathrm{y}=6 ; \mathrm{z}=-30$, respectively), whereas the mesocortical pathway was found in only 51 voxels ( $\mathrm{T}_{\max }$ at 4.2 with $\mathrm{MNI}$ coordinates $\left.\mathrm{x}=-2 ; \mathrm{y}=46 ; \mathrm{z}=24\right)$. Otherwise, 3,306 significant voxels corresponding to $75 \%$ of the total significant voxels volume were found outside these pathways (thalamus, insula and motor cortex).

The findings of midbrain connectivity obtained with ${ }^{18}$ F-FDOPA PET imaging were the most significant, with a similar T-voxel threshold value of 5.10 as that applied for ${ }^{18}$ F-FDG PET imaging. These findings are reported in Table 3 and Figure 4. The 3 dopaminergic pathways were correctly identified with a total of 6,054 voxels. The mesocortical pathway, which was hardly revealed with the two other radiotracers, was particularly well defined (2,188 voxels, $\mathrm{T}_{\max }$ at 8.6 with MNI coordinates $\left.\mathrm{x}=-10 ; \mathrm{y}=66 ; \mathrm{z}=-14\right)$, in addition to the two other dopaminergic pathways $\left(2,330\right.$ voxels and $T_{\max }$ at 10.4 with MNI coordinates $x=-10 ; y=0 ; z=-$ 6 for the nigrostriatal pathway; 1,536 voxels and $\mathrm{T}_{\max }$ at 11.7 with $\mathrm{MNI}$ coordinates $\mathrm{x}=-22$; $y=-24 ; z=-12$ for the mesolimbic pathway). Concomitantly, the number of significant voxels outside the dopaminergic system was reduced in comparison to the two other radiotracers with a volume of 11,248 voxels ( $65 \%$ of the total volume of significant voxels) involving the thalamus, insula and the motor cortex.

Figure 5 illustrates the midbrain's connectivity findings obtained with ${ }^{18}$ F-FDOPA PET and not with ${ }^{18}$ F-FDG PET for the same T-voxel threshold value of 5.10. ${ }^{18}$ F-FDOPA PET imaging identified 13 clusters in the 3 dopaminergic pathways not found with ${ }^{18}$ F-FDG PET (4,708 voxels, Figure 5A and Table 4; in details 1,945 voxels in the nigrostriatal pathway; 727 
voxels in the mesolimbic pathway; and 2,036 voxels in the mesocortical pathway).

Conversely, ${ }^{18}$ F-FDG PET imaging revealed findings outside the mesotelencephalic system, not found with ${ }^{18}$ F-FDOPA PET (in the cerebellum and in premotor and sensory-motor cortices (BA 3-4-6), corresponding to 9,323 voxels, Figure 5B). As previously mentioned, at this T-voxel threshold of 5.10, no significant findings were observed with ${ }^{123}$ I-FP-CIT SPECT.

\section{Discussion}

This study aimed to assess the feasibility and potential of molecular connectivity based on neurotransmission in comparison to the metabolic one with an application to dopaminergic pathways. The results show that the neurotransmission connectivity better reveals the mesotelencephalic system than the metabolic connectivity, and in particular with higher specificity. Moreover, the mesotelencephalic system was better revealed with ${ }^{18}$ F-FDOPA than with ${ }^{123}$ I-FP-CIT, confirming that the two dopaminergic targets are not equivalent.

This system with its 3 main dopaminergic pathways is well defined in the literature [18-20], and the midbrain area is the starting point of these 3 distinct pathways [40]. Therefore, based on this documented hypothesis, we focused on the midbrain's connectivity using the IRCA method to study the neurotransmission connectivity of the dopaminergic system. To be consistent with the spatial resolution across imaging modalities, in particular SPECT, the total volume of the midbrain was selected as the region of interest to characterize connectivity of the SN and the VTA. This choice is debatable owing to the large volume of the midbrain area relative to the small structural volumes of the SN and VTA. However, it is consistent with the current view of a continuum in the midbrain between these structures (each structure being associated with different mesotelencephalic pathways), and that other structures of the midbrain could be also implicated in these pathways, such as the retrorubral field [19,24,38]. 
The metabolic connectivity studied herein with ${ }^{18}$ F-FDG PET highlighted the mesotelencephalic system well (Figure 2), even if the identification of mesocortical pathway was more limited as compared to the 2 other pathways. Extensive significant clusters were also found outside the mesotelencephalic system ( $89 \%$ of the total volume of significant voxels with more than $45 \%$ of clusters in the cerebellum), underscoring the fact that ${ }^{18}$ F-FDG is a PET glycolytic radiotracer indicative of global synaptic activity [26], and not restrictive of a particular neurotransmitter system. In this line, it has been previously reported that the midbrain constitutes a "connector" hub with a high level of connectivity to other systems than the dopaminergic pathways [41]. The high metabolic connectivity found in the present study outside the dopaminergic pathways is thus not surprising. It may constitute a competitive advantage for global evaluation not restricted to a specific neurotransmission system. In case of studying more specific systems, these ${ }^{18}$ F-FDG PET findings show nevertheless that molecular connectivity based on neurotransmission could be prioritized.

To date, dopaminergic neurotransmission connectivity using ${ }^{123}$ I-FP-CIT SPECT has been little reported. Only one study using IRCA of the left putamen showed that in patients with impulse control disorders in Parkinson's disease, an asymmetric dopaminergic frontostriatal network breakdown was found in comparison to patients with Parkinson's disease but no impulse control disorders [42]. Our study aimed to reveal the mesotelencephalic dopamine system in subjects without any neurodegenerative disorders. An original point is that healthy subjects studied with ${ }^{123}$ I-FP-CIT SPECT were the same as those subjects studied with ${ }^{18} \mathrm{~F}$ FDG PET imaging, allowing the direct comparison between the metabolic and molecular connectivity patterns. ${ }^{123}$ I-FP-CIT SPECT did not provide additional information within the mesotelencephalic system in comparison to ${ }^{18} \mathrm{~F}$-FDG PET, owing to a lower spatial resolution related to the SPECT technology itself [43]. However, by using a less restrictive T-voxel threshold value of 2.80 , the percentage of significant voxels belonging to the 
mesotelencephalic system was significant with ${ }^{123}$ I-FP-CIT SPECT (25\%), confirming the relative high specificity obtained with dopaminergic connectivity analyses.

These results with ${ }^{123}$ I-FP-CIT SPECT were strengthened by results obtained with ${ }^{18} \mathrm{~F}$ FDOPA PET. As visualized in Figure $4,{ }^{18}$ F-FDOPA PET revealed the 3 main dopaminergic pathways with a high specificity (35\% of the total volume of significant voxels belonged to the mesotelencephalic system). ${ }^{18}$ F-FDOPA PET revealed larger extended areas within the dopaminergic pathways than ${ }^{18}$ F-FDG PET (+4,708 voxels) at the T-voxel threshold value of 5.10 whereas no significant voxels were obtained with ${ }^{123}$ I-FP-CIT SPECT at this threshold. Interestingly, at this same T-voxel threshold value, findings outside the dopaminergic system were clearly wider with ${ }^{18} \mathrm{~F}$-FDG PET imaging, as compared to ${ }^{18} \mathrm{~F}$-FDOPA PET, confirming that molecular connectivity through dopaminergic neurotransmission is more specific than metabolic connectivity. In addition, the sensitivity for revealing the 3 dopaminergic pathways was excellent with ${ }^{18}$ F-FDOPA PET, especially for the mesocortical pathway, which was hardly revealed with the two other tracers. These findings highlight the importance of the choice of the correct target to assess molecular connectivity. To date, only three studies have examined dopaminergic connectivity with the PET modality $[13,44,45]$. The first study targeted postsynaptic dopamine D2 receptors in control subjects but did not find significant correlations between the striatum and extrastriatal areas using IRCA with different ROIs which did not include the midbrain [44]. The second study, a presynaptic dopamine transporter (DaT) study, used partial correlation analyses of a network involving ROIs in the nigrostriatal and mesolimbic pathways in patients with early Parkinson's disease and controls [45]. The authors found a decrease in connectivity within the nigrostriatal pathway in patients with early Parkinson's disease [45]. The third study using ${ }^{18}$ F-FDOPA PET in 52 healthy subjects aimed to assess the feasibility of graph theory analysis [13]. 
Several limitations are inherent to the current study. Two different modalities and two different sets of subjects were studied. A similar T-voxel threshold value was nevertheless applied through the 2 different imaging modalities and 3 radiotracers to perform comparisons between them. Some authors have reported that the limitation of molecular connectivity could be related to correlated noise between areas, especially linked to the nonspecific binding of such tracers, which induce false positive results [46]. In the current study, an area of whitematter binding was used as a covariate to take into account the potential effect of nonspecific binding in molecular imaging, and corrections for multiple comparisons were systematically applied in the statistical analyses. Finally, the present study did not focus on the dopamine tuberoinfundibular pathway since it does not arise from the midbrain. This dopaminergic pathway consists of dopaminergic neurons from the arcuate nucleus of the hypothalamus to the median eminence of the anterior pituitary and is mainly responsible for the inhibition of prolactin secretion [25].

To summarize, the present study illustrates the feasibility and interest in using molecular connectivity with ${ }^{18}$ F-FDOPA PET imaging regarding dopaminergic pathways. This is the first study to directly compare dopaminergic neurotransmission connectivity with the metabolic connectivity, highlighting the advantages of such an approach in terms of sensitivity and specificity. The choice of imaging modality and neurotransmitter targeting is also crucial, as shown here, with the difference in findings between ${ }^{123}$ I-FP-CIT SPECT and ${ }^{18}$ F-FDOPA PET. On the other hand, this innovative approach allows extending the current metabolic connectivity to the neurotransmitter level through known anatomical connections. Further studies will be necessary to specify the relationships with functional and structural MRI connectivity, and the complementarity of these approaches.

Such analyses could be mostly be applied to specific diseases involving the mesotelencephalic system, and potentially with other molecular SPECT/PET targets to other systems. 


\section{Compliance with Ethical Standards}

Funding: This work was carried out thanks to the support of the A*MIDEX project $\left(\mathrm{n}^{\circ} \mathrm{ANR}-\right.$ 11-IDEX-0001-02) funded by the "Investissements d'Avenir" French Government program, managed by the French National Research Agency (ANR).

Conflict of Interest: The authors declare that they have no conflict of interest.

Ethical approval: All procedures performed in studies involving human participants were in accordance with the ethical standards of the institutional and/or national research committee and with the 1964 Helsinki Declaration and its later amendments or comparable ethical standards.

Informed consent: Informed written consent was obtained from all individual participants included in the study. 


\section{References}

1. Horwitz B, Duara R, Rapoport SI. Intercorrelations of glucose metabolic rates between brain regions: application to healthy males in a state of reduced sensory input. J Cereb Blood Flow Metab Off J Int Soc Cereb Blood Flow Metab. 1984;4:484-99.

2. Metter EJ, Riege WH, Kameyama M, Kuhl DE, Phelps ME. Cerebral metabolic relationships for selected brain regions in Alzheimer's, Huntington's, and Parkinson's diseases. J Cereb Blood Flow Metab Off J Int Soc Cereb Blood Flow Metab. 1984;4:500-6.

3. Clark CM, Stoessl AJ. Glucose use correlations: a matter of inference. J Cereb Blood Flow Metab Off J Int Soc Cereb Blood Flow Metab. 1986;6:511-2.

4. Yakushev I, Drzezga A, Habeck C. Metabolic connectivity: methods and applications. Curr Opin Neurol. 2017;30:677-85.

5. Verger A, Klesse E, Chawki MB, Witjas T, Azulay J-P, Eusebio A, et al. Brain PET substrate of impulse control disorders in Parkinson's disease: A metabolic connectivity study. Hum Brain Mapp. 2018;39:3178-86.

6. The REMPET Study Group Sittig-Wiegand Elisabeth f Depboylu Candan f Reetz Kathrin 1 Overeem Sebastiaan m Pijpers Angelique m Reesink Fransje E. b van Laar Teus b Teune Laura K. b Höffken Helmut n Luster Marcus n Timmermann Lars f Kesper Karl o Adriaanse Sofie M. p Booij Jan p Sambuceti Gianmario d Girtler Nicola a, Arnaldi D, Meles SK, Giuliani A, Morbelli S, Renken RJ, et al. Brain Glucose Metabolism Heterogeneity in Idiopathic REM Sleep Behavior Disorder and in Parkinson's Disease. J Park Dis. 2019;9:229-39.

7. Lee DS, Kang H, Kim H, Park H, Oh JS, Lee JS, et al. Metabolic connectivity by interregional correlation analysis using statistical parametric mapping (SPM) and FDG brain PET; methodological development and patterns of metabolic connectivity in adults. Eur J Nucl Med Mol Imaging. 2008;35:1681-91.

8. Morbelli S, Drzezga A, Perneczky R, Frisoni GB, Caroli A, van Berckel BNM, et al. Resting metabolic connectivity in prodromal Alzheimer's disease. A European Alzheimer Disease Consortium (EADC) project. Neurobiol Aging. 2012;33:2533-50.

9. Gardner A, Åstrand D, Öberg J, Jacobsson H, Jonsson C, Larsson S, et al. Towards mapping the brain connectome in depression: Functional connectivity by perfusion SPECT. Psychiatry Res Neuroimaging. 2014;223:171-7.

10. Hahn A, Lanzenberger R, Kasper S. Making Sense of Connectivity. Int J Neuropsychopharmacol. 2019;22:194-207.

11. Tuominen L, Nummenmaa L, Keltikangas-Järvinen L, Raitakari O, Hietala J. Mapping neurotransmitter networks with PET: An example on serotonin and opioid systems: Mapping Neurotransmitter Networks With PET. Hum Brain Mapp. 2014;35:1875-84.

12. Vanicek T, Kutzelnigg A, Philippe C, Sigurdardottir HL, James GM, Hahn A, et al. Altered interregional molecular associations of the serotonin transporter in attention deficit/hyperactivity disorder assessed with PET. Hum Brain Mapp. 2017;38:792-802. 
13. Veronese M, Moro L, Arcolin M, Dipasquale O, Rizzo G, Expert P, et al. Covariance statistics and network analysis of brain PET imaging studies. Sci Rep. 2019;9:2496.

14. Carlsson A, Lindqvist M, Magnusson T, Waldeck B. On the presence of 3hydroxytyramine in brain. Science. 1958;127:471.

15. Cooper DC. The significance of action potential bursting in the brain reward circuit. Neurochem Int. 2002;41:333-40.

16. Floresco SB, Magyar O. Mesocortical dopamine modulation of executive functions: beyond working memory. Psychopharmacology (Berl). 2006;188:567-85.

17. Haber SN, Knutson B. The reward circuit: linking primate anatomy and human imaging. Neuropsychopharmacol Off Publ Am Coll Neuropsychopharmacol. 2010;35:4-26.

18. Fuxe K, Agnati LF, Kalia M, Goldstein M, Andersson K, Härfstrand A. Dopaminergic Systems in the Brain and Pituitary. Dopaminergic Syst [Internet]. Berlin, Heidelberg: Springer Berlin Heidelberg; 1985 [cited 2019 Apr 8]. p. 11-25. Available from: http://www.springerlink.com/index/10.1007/978-3-642-69948-1_2

19. Bloom FE, Björklund A, Hökfelt T. The primate nervous system. Part I. Amsterdam; New York: Elsevier; 1997.

20. Dunnett SB. Dopamine [Internet]. Amsterdam; Boston: Elsevier; 2005 [cited 2019 Apr 8]. Available from: http://www.sciencedirect.com/science/book/9780444517784

21. Anden NE, Carlsson A, Dahlstroem A, Fuxe K, Hillarp NA, Larsson K. DEMONSTRATION AND MAPPING OUT OF NIGRO-NEOSTRIATAL DOPAMINE NEURONS. Life Sci 1962. 1964;3:523-30.

22. Andén N-E, Dahlström A, Fuxe K, Larsson K. Further evidence for the presence of nigroneostriatal dopamine neurons in the rat: NIGRO-NEOSTRIATAL DOPAMINE NEURONS. Am J Anat. 1965;116:329-33.

23. Hu Z, Cooper M, Crockett DP, Zhou R. Differentiation of the midbrain dopaminergic pathways during mouse development. J Comp Neurol. 2004;476:301-11.

24. Gerfen CR. Functional Neuroanatomy of Dopamine in the Striatum. In: Iversen L, Iversen S, Dunnett S, Bjorklund A, editors. Dopamine Handb [Internet]. Oxford University Press; 2009 [cited 2019 Apr 8]. p. 11-21. Available from:

http://www.oxfordscholarship.com/view/10.1093/acprof:oso/9780195373035.001.0001/acpro f-9780195373035-chapter-2

25. Nestler EJ, Hyman SE, Malenka RC. Molecular neuropharmacology: a foundation for clinical neuroscience. 2nd ed. New York: McGraw-Hill Medical; 2009.

26. Magistretti PJ, Pellerin L. Cellular mechanisms of brain energy metabolism and their relevance to functional brain imaging. Philos Trans R Soc Lond B Biol Sci. 1999;354:115563. 
27. Eusebio A, Azulay J-P, Ceccaldi M, Girard N, Mundler O, Guedj E. Voxel-based analysis of whole-brain effects of age and gender on dopamine transporter SPECT imaging in healthy subjects. Eur J Nucl Med Mol Imaging. 2012;39:1778-83.

28. Darcourt J, Schiazza A, Sapin N, Dufour M, Ouvrier MJ, Benisvy D, et al. 18F-FDOPA PET for the diagnosis of parkinsonian syndromes. Q J Nucl Med Mol Imaging Off Publ Ital Assoc Nucl Med AIMN Int Assoc Radiopharmacol IAR Sect Soc Of. 2014;58:355-65.

29. Toch S-R, Poussier S, Micard E, Bertaux M, Van Der Gucht A, Chevalier E, et al. Physiological Whole-Brain Distribution of [18F]FDOPA Uptake Index in Relation to Age and Gender: Results from a Voxel-Based Semi-quantitative Analysis. Mol Imaging Biol [Internet]. 2018 [cited 2019 Mar 11]; Available from: http://link.springer.com/10.1007/s11307-018-1256-1

30. Hoffman JM, Melega WP, Hawk TC, Grafton SC, Luxen A, Mahoney DK, et al. The effects of carbidopa administration on 6-[18F]fluoro-L-dopa kinetics in positron emission tomography. J Nucl Med Off Publ Soc Nucl Med. 1992;33:1472-7.

31. Verger A, Roman S, Chaudat R-M, Felician O, Ceccaldi M, Didic M, et al. Changes of metabolism and functional connectivity in late-onset deafness: Evidence from cerebral 18FFDG-PET. Hear Res. 2017;353:8-16.

32. Kas A, Payoux P, Habert M-O, Malek Z, Cointepas Y, El Fakhri G, et al. Validation of a Standardized Normalization Template for Statistical Parametric Mapping Analysis of 123IFP-CIT Images. J Nucl Med. 2007;48:1459-67.

33. Jokinen P, Helenius H, Rauhala E, Brück A, Eskola O, Rinne JO. Simple ratio analysis of 18F-fluorodopa uptake in striatal subregions separates patients with early Parkinson disease from healthy controls. J Nucl Med Off Publ Soc Nucl Med. 2009;50:893-9.

34. Tzourio-Mazoyer N, Landeau B, Papathanassiou D, Crivello F, Etard O, Delcroix N, et al. Automated anatomical labeling of activations in SPM using a macroscopic anatomical parcellation of the MNI MRI single-subject brain. NeuroImage. 2002;15:273-89.

35. Lieberman MD, Cunningham WA. Type I and Type II error concerns in fMRI research: re-balancing the scale. Soc Cogn Affect Neurosci. 2009;4:423-8.

36. Lindvall O, Björklund A. Dopaminergic innervation of the globus pallidus by collaterals from the nigrostriatal pathway. Brain Res. 1979;172:169-73.

37. Sanchez-Gonzalez MA. The Primate Thalamus Is a Key Target for Brain Dopamine. J Neurosci. 2005;25:6076-83.

38. Gardner EL, Ashby CR. Heterogeneity of the mesotelencephalic dopamine fibers: physiology and pharmacology. Neurosci Biobehav Rev. 2000;24:115-8.

39. Hosp JA, Luft AR. Dopaminergic Meso-Cortical Projections to M1: Role in Motor Learning and Motor Cortex Plasticity. Front Neurol [Internet]. 2013 [cited 2019 Apr 8];4. Available from: http://journal.frontiersin.org/article/10.3389/fneur.2013.00145/abstract 
40. Meck WH. Neuroanatomical localization of an internal clock: A functional link between mesolimbic, nigrostriatal, and mesocortical dopaminergic systems. Brain Res. 2006;1109:93107.

41. Bär K-J, de la Cruz F, Schumann A, Koehler S, Sauer H, Critchley H, et al. Functional connectivity and network analysis of midbrain and brainstem nuclei. NeuroImage.

2016;134:53-63.

42. Premi E, Pilotto A, Garibotto V, Bigni B, Turrone R, Alberici A, et al. Impulse control disorder in PD: A lateralized monoaminergic frontostriatal disconnection syndrome?

Parkinsonism Relat Disord. 2016;30:62-6.

43. Rahmim A, Zaidi H. PET versus SPECT: strengths, limitations and challenges. Nucl Med Commun. 2008;29:193-207.

44. Cervenka S, Varrone A, Fransén E, Halldin C, Farde L. PET studies of D2-receptor binding in striatal and extrastriatal brain regions: Biochemical support in vivo for separate dopaminergic systems in humans. Synap N Y N. 2010;64:478-85.

45. Caminiti SP, Presotto L, Baroncini D, Garibotto V, Moresco RM, Gianolli L, et al. Axonal damage and loss of connectivity in nigrostriatal and mesolimbic dopamine pathways in early Parkinson's disease. NeuroImage Clin. 2017;14:734-40.

46. Hahn A, Lanzenberger R, Wadsak W, Spindelegger C, Moser U, Mien L-K, et al. Escitalopram enhances the association of serotonin-1A autoreceptors to heteroreceptors in anxiety disorders. J Neurosci Off J Soc Neurosci. 2010;30:14482-9. 
Table 1. Findings of ${ }^{18}$ F-FDG PET midbrain connectivity within dopaminergic pathways (mesotelencephalic pathway involved, anatomical locations, the spatial extent of significant clusters in voxels, MNI coordinates, and maximal T-scores of the peak voxel) at a T-voxel threshold of 5.10 , $\mathrm{k}$ cluster size $>20$ voxels.

\begin{tabular}{|c|c|c|c|c|c|c|}
\hline Mesotelencephalic pathway & Anatomical location & Cluster dimension & $\mathbf{x}$ & $\mathbf{y}$ & $\mathbf{z}$ & $\begin{array}{l}\text { T-score } \\
\text { of peak }\end{array}$ \\
\hline \multirow[t]{2}{*}{ Nigrostriatal } & $\begin{array}{l}\text { Right cerebrum : } \\
\text { - } \quad \text { Caudate } \\
\text { - } \quad \text { Putamen } \\
\text { - } \quad \text { Pallidum }\end{array}$ & 220 & 16 & -2 & -6 & 9.6 \\
\hline & 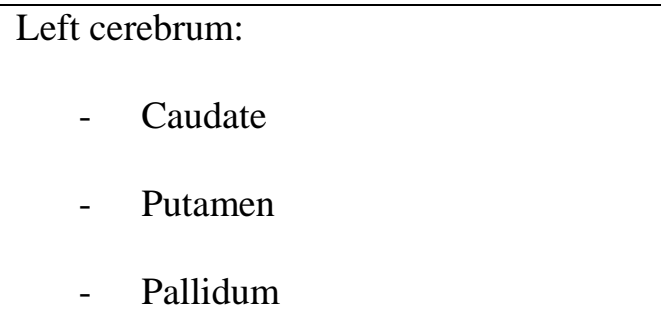 & 189 & -16 & -4 & -6 & 8.0 \\
\hline \multirow[t]{2}{*}{ Mesolimbic } & $\begin{array}{l}\text { Right cerebrum: } \\
\begin{array}{ll}- & \text { Amygdala } \\
- & \text { Hippocampus } \\
- & \text { Parahippocampus } \\
- & \text { Internal temporal (BA 27-28-34- } \\
35-36)\end{array}\end{array}$ & 417 & 16 & -6 & -14 & 12.6 \\
\hline & $\begin{array}{l}\text { Left cerebrum: } \\
\begin{array}{ll}- & \text { Amygdala } \\
- & \text { Hippocampus } \\
- & \text { Parahippocampus } \\
- & \text { Internal temporal (BA 27-28-34- } \\
& 35-36)\end{array}\end{array}$ & 311 & -16 & -28 & -8 & 11.0 \\
\hline
\end{tabular}




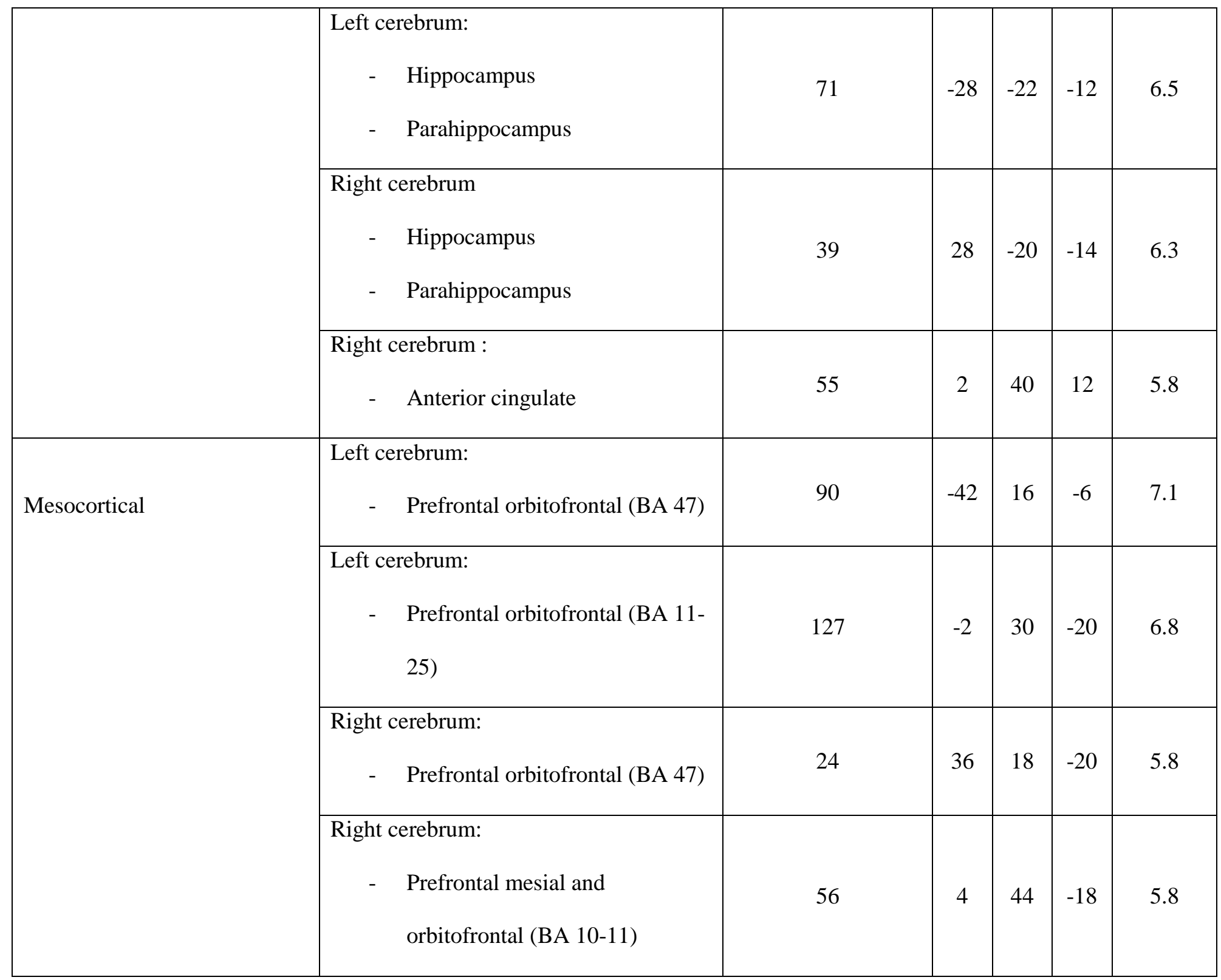

BA: Brodmann area 
Table 2. Findings of ${ }^{123}$ I-FP-CIT SPECT midbrain connectivity within dopaminergic pathways (mesotelencephalic pathway involved, anatomical locations, the spatial extent of significant clusters in voxels, MNI coordinates, maximal T-scores of the peak voxel) at a Tvoxel threshold of $2.80, \mathrm{k}$ cluster size $>50$ voxels.

\begin{tabular}{|c|c|c|c|c|c|c|}
\hline Mesotelencephalic pathway & Anatomical location & Cluster dimension & $\mathbf{x}$ & $\mathbf{y}$ & $\mathbf{z}$ & $\begin{array}{l}\text { T-score } \\
\text { of peak }\end{array}$ \\
\hline \multirow[t]{2}{*}{ Nigrostriatal } & $\begin{array}{l}\text { Left cerebrum: } \\
\begin{array}{cc}\text { - } & \text { Caudate } \\
\text { - } & \text { Putamen } \\
\text { - } & \text { Pallidum }\end{array}\end{array}$ & 473 & -22 & 0 & -4 & 5.1 \\
\hline & $\begin{array}{c}\text { Right cerebrum : } \\
\text { - } \quad \text { Caudate } \\
\text { - } \quad \text { Putamen } \\
\text { - Pallidum }\end{array}$ & 181 & 10 & 8 & -12 & 4.7 \\
\hline \multirow[t]{3}{*}{ Mesolimbic } & 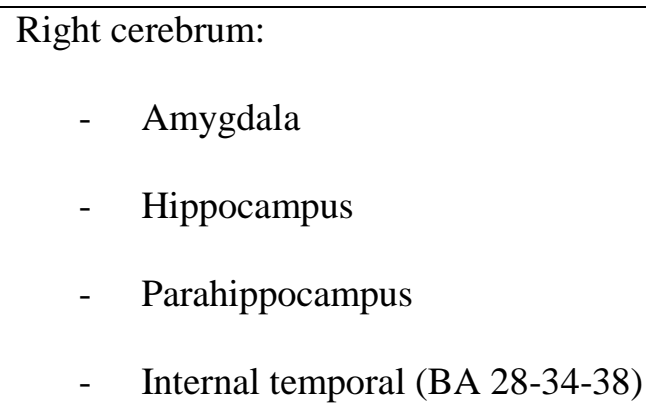 & 204 & 20 & 6 & -30 & 5.0 \\
\hline & $\begin{array}{l}\text { Left cerebrum: } \\
\begin{array}{ll}\text { - } & \text { Amygdala } \\
\text { - } & \text { Hippocampus } \\
\text { - } & \text { Parahippocampus } \\
\text { - } & \text { Internal temporal (BA 28-34) }\end{array}\end{array}$ & 211 & -18 & 0 & -14 & 4.0 \\
\hline & $\begin{array}{l}\text { Left cerebrum: } \\
\text { - } \quad \text { Prefrontal dorsolateral (BA 9) }\end{array}$ & 51 & -2 & 46 & 24 & 4.2 \\
\hline
\end{tabular}


Table 3. Findings of ${ }^{18}$ F-FDOPA PET midbrain connectivity within dopaminergic pathways (mesotelencephalic pathway involved, anatomical locations, the spatial extent of significant clusters in voxels, MNI coordinates, maximal T-scores of the peak voxel) at a T-voxel threshold of 5.10 , $\mathrm{k}$ cluster size $>20$ voxels.

\begin{tabular}{|c|c|c|c|c|c|c|}
\hline Mesotelencephalic pathway & Anatomical location & Cluster dimension & $\mathbf{x}$ & $\mathbf{y}$ & $\mathbf{z}$ & $\begin{array}{l}\text { T-score } \\
\text { of peak }\end{array}$ \\
\hline \multirow[t]{2}{*}{ Nigrostriatal } & $\begin{array}{l}\text { Left cerebrum: } \\
\begin{array}{c}\text { - } \\
\text { - }\end{array} \text { Paudate } \\
\text { - } \quad \text { Pallidumen }\end{array}$ & 1173 & -10 & 0 & -6 & 10.4 \\
\hline & $\begin{array}{c}\text { Right cerebrum: } \\
\text { - } \quad \text { Caudate } \\
\text { - } \quad \text { Putamen } \\
\text { - } \quad \text { Pallidum }\end{array}$ & 1157 & 16 & 20 & 2 & 9.9 \\
\hline \multirow[t]{3}{*}{ Mesolimbic } & $\begin{array}{l}\text { Right cerebrum: } \\
\begin{array}{l}\text { - } \\
\text { - }\end{array} \text { Hipygdala } \\
-\quad \text { Parahippocampus } \\
\text { - } \text { Internal temporal (BA 28-34-35- } \\
\text { 36) }\end{array}$ & 554 & 22 & -24 & -12 & 11.7 \\
\hline & 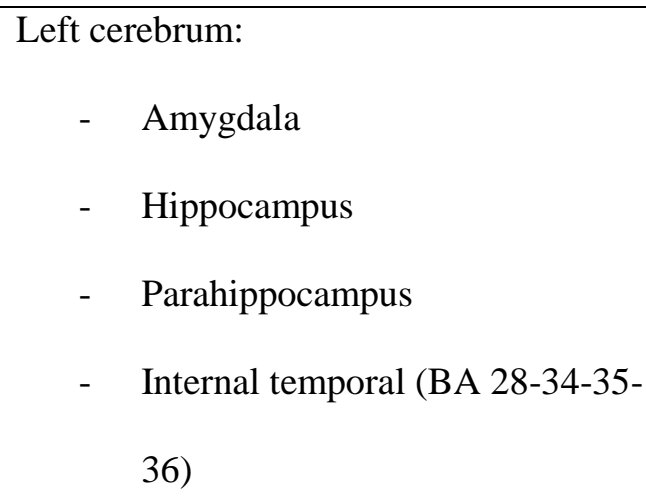 & 509 & -16 & -12 & -14 & 11.4 \\
\hline & $\begin{array}{l}\text { Right cerebrum: } \\
\text { - } \quad \text { Anterior and middle cingulate }\end{array}$ & 280 & 4 & 0 & 36 & 7.0 \\
\hline
\end{tabular}




\begin{tabular}{|c|c|c|c|c|c|c|}
\hline & $\begin{array}{l}\text { Left cerebrum: } \\
\text { - } \quad \text { Anterior and middle cingulate }\end{array}$ & 70 & -2 & 0 & 36 & 6.6 \\
\hline & $\begin{array}{l}\text { Left cerebrum } \\
-\quad \text { Anterior cingulate }\end{array}$ & 123 & -2 & 48 & 4 & 5.9 \\
\hline \multirow[t]{5}{*}{ Mesocortical } & $\begin{array}{l}\text { Left cerebrum: } \\
\begin{array}{l}\text { - } \\
\text { Prefrontal mesial and } \\
\text { orbitofrontal (BA 10-11-47) }\end{array}\end{array}$ & 1088 & -10 & 66 & -14 & 8.6 \\
\hline & 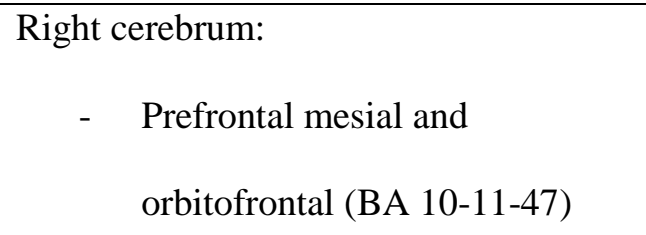 & 1015 & 8 & 22 & -14 & 7.8 \\
\hline & $\begin{array}{l}\text { Right cerebrum: } \\
\text { - } \quad \text { Prefrontal orbitofrontal (BA 47) }\end{array}$ & 29 & 42 & 30 & -14 & 5.9 \\
\hline & $\begin{array}{l}\text { Right cerebrum: } \\
\text { - } \quad \text { Prefrontal mesial (BA 10) }\end{array}$ & 31 & 2 & 48 & 4 & 5.9 \\
\hline & $\begin{array}{l}\text { Left cerebrum : } \\
\text { - } \quad \text { Prefrontal dorsolateral (BA 9) }\end{array}$ & 25 & -2 & 42 & 28 & 5.5 \\
\hline
\end{tabular}

BA: Brodmann area 
Table 4. Clusters within dopaminergic pathways identified by ${ }^{18} \mathrm{~F}-\mathrm{FDOPA}$ PET and not by ${ }^{18}$ F-FDG PET (mesotelencephalic pathway involved, anatomical locations, the spatial extent of significant clusters in voxels, MNI coordinates, maximal T-scores of the peak voxel) at a Tvoxel threshold of 5.10 , $\mathrm{k}$ cluster size $>20$ voxels.

\begin{tabular}{|c|c|c|c|c|c|c|}
\hline Mesotelencephalic pathway & Anatomical location & Cluster dimension & $\mathbf{x}$ & $\mathbf{y}$ & $\mathbf{z}$ & $\begin{array}{l}\text { T-score } \\
\text { of peak }\end{array}$ \\
\hline \multirow[t]{2}{*}{ Nigrostriatal } & $\begin{array}{r}\text { Right cerebrum: } \\
\text { - } \quad \text { Caudate } \\
\text { - } \quad \text { Putamen } \\
\text { - } \quad \text { Pallidum }\end{array}$ & 948 & 16 & 20 & 2 & 9.9 \\
\hline & $\begin{array}{l}\text { Left cerebrum: } \\
\begin{array}{c}\text { - } \\
\text { - }\end{array} \text { Paudate } \\
\text { - } \quad \text { Pallidumen }\end{array}$ & 992 & -12 & 20 & -4 & 9.9 \\
\hline \multirow[t]{4}{*}{ Mesolimbic } & $\begin{array}{l}\text { Left cerebrum: } \\
\begin{array}{ll}\text { - } & \text { Amygdala } \\
- & \text { Hippocampus } \\
- & \text { Parahippocampus } \\
\text { - } & \text { Internal temporal (BA 28-34) }\end{array}\end{array}$ & 155 & -24 & -4 & -20 & 10.6 \\
\hline & $\begin{array}{l}\text { Right cerebrum: } \\
\begin{array}{l}\text { - } \\
\text { - }\end{array} \text { Himygdala } \\
\text { - } \quad \text { Parahippocampus } \\
\end{array}$ & 65 & 32 & -18 & -18 & 7.9 \\
\hline & $\begin{array}{l}\text { Right cerebrum } \\
\text { - } \quad \text { Anterior and middle cingulate }\end{array}$ & 167 & 4 & 0 & 36 & 7.0 \\
\hline & $\begin{array}{l}\text { Left cerebrum: } \\
\text { - } \quad \text { Anterior and middle cingulate }\end{array}$ & 70 & -2 & 0 & 36 & 6.6 \\
\hline
\end{tabular}




\begin{tabular}{|c|c|c|c|c|c|c|}
\hline & $\begin{array}{l}\text { Right cerebrum: } \\
\text { - } \quad \text { Anterior cingulate }\end{array}$ & 72 & 4 & 46 & 12 & 6.1 \\
\hline & $\begin{array}{l}\text { Left cerebrum } \\
-\quad \text { Anterior cingulate }\end{array}$ & 123 & -2 & 48 & 4 & 5.9 \\
\hline \multirow[t]{5}{*}{ Mesocortical } & $\begin{array}{l}\text { Left cerebrum : } \\
\begin{array}{l}\text { - } \\
\text { Prefrontal mesial and } \\
\text { orbitofrontal (BA 10-11-47) }\end{array}\end{array}$ & 988 & -10 & 66 & -14 & 8.6 \\
\hline & 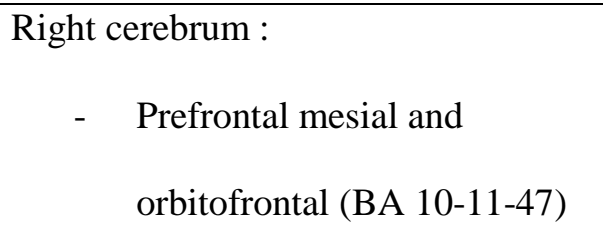 & 957 & 8 & 22 & -14 & 7.8 \\
\hline & 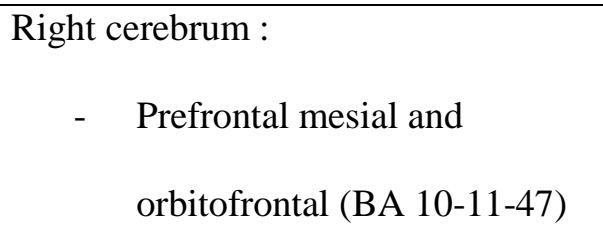 & 29 & 42 & 30 & -14 & 5.9 \\
\hline & $\begin{array}{l}\text { Right cerebrum: } \\
\text { - } \quad \text { Prefrontal mesial (BA 10) }\end{array}$ & 29 & 2 & 48 & 4 & 5.9 \\
\hline & $\begin{array}{l}\text { Left cerebrum : } \\
\text { - } \quad \text { Prefrontal dorsolateral (BA 9) }\end{array}$ & 25 & -2 & 42 & 28 & 5.5 \\
\hline
\end{tabular}

BA: Brodmann area 
Figure 1. Flowchart for subjects' selection and image processing of ${ }^{18}$ F-FDG PET, ${ }^{123}$ I-FPCIT SPECT and ${ }^{18}$ F-FDOPA PET imaging

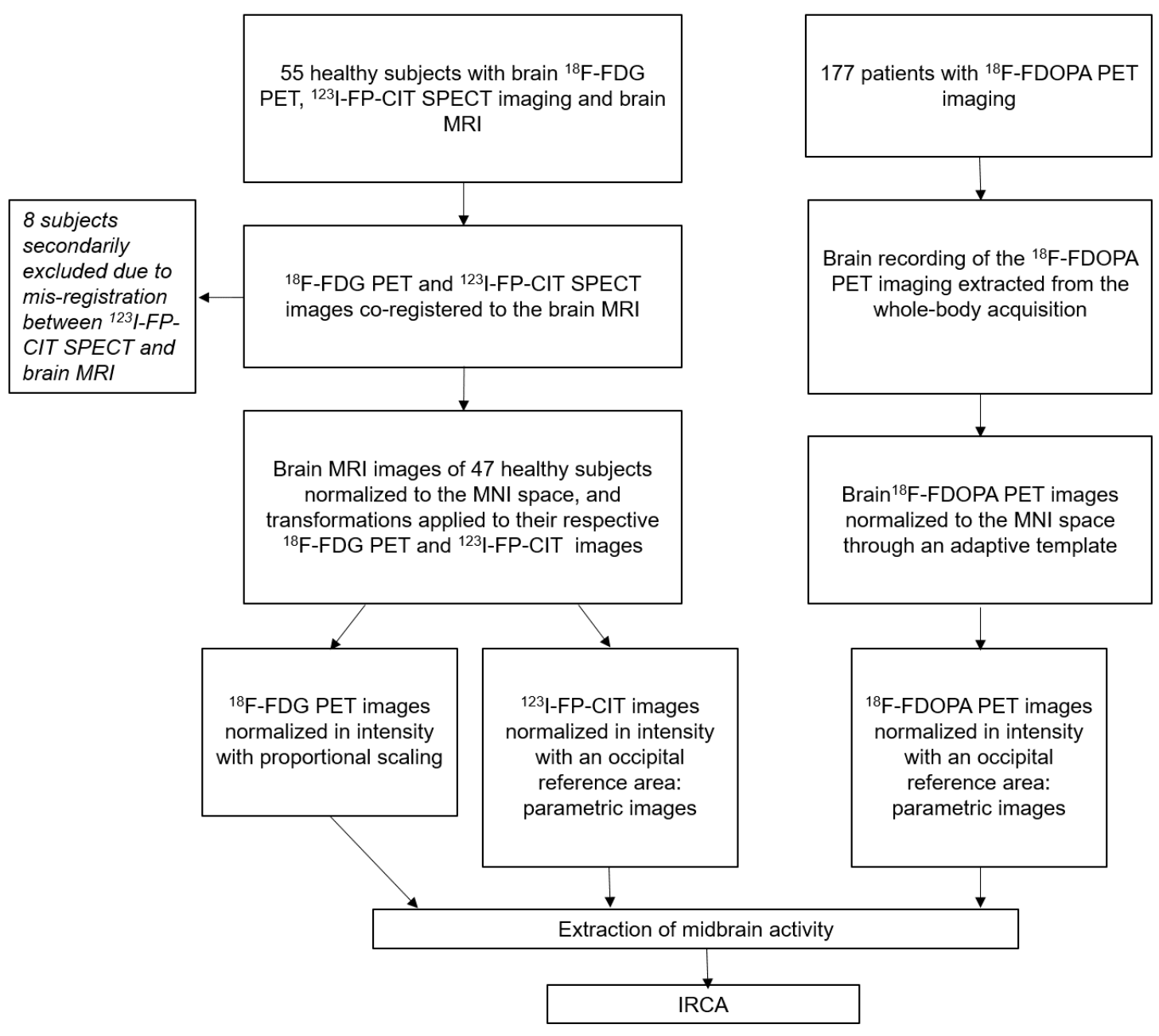

IRCA: interregional correlation analysis; MNI: Montreal National Institute 
Figure 2. Anatomical localization of the 3 mesotelencephalic pathways identified by the ${ }^{18} \mathrm{~F}$ -

FDG midbrain's connectivity analysis (T-voxel threshold of 5.10; k cluster size >20 voxels) projected onto 3D volume rendering, spatially normalized and smoothed into the standard SPM template

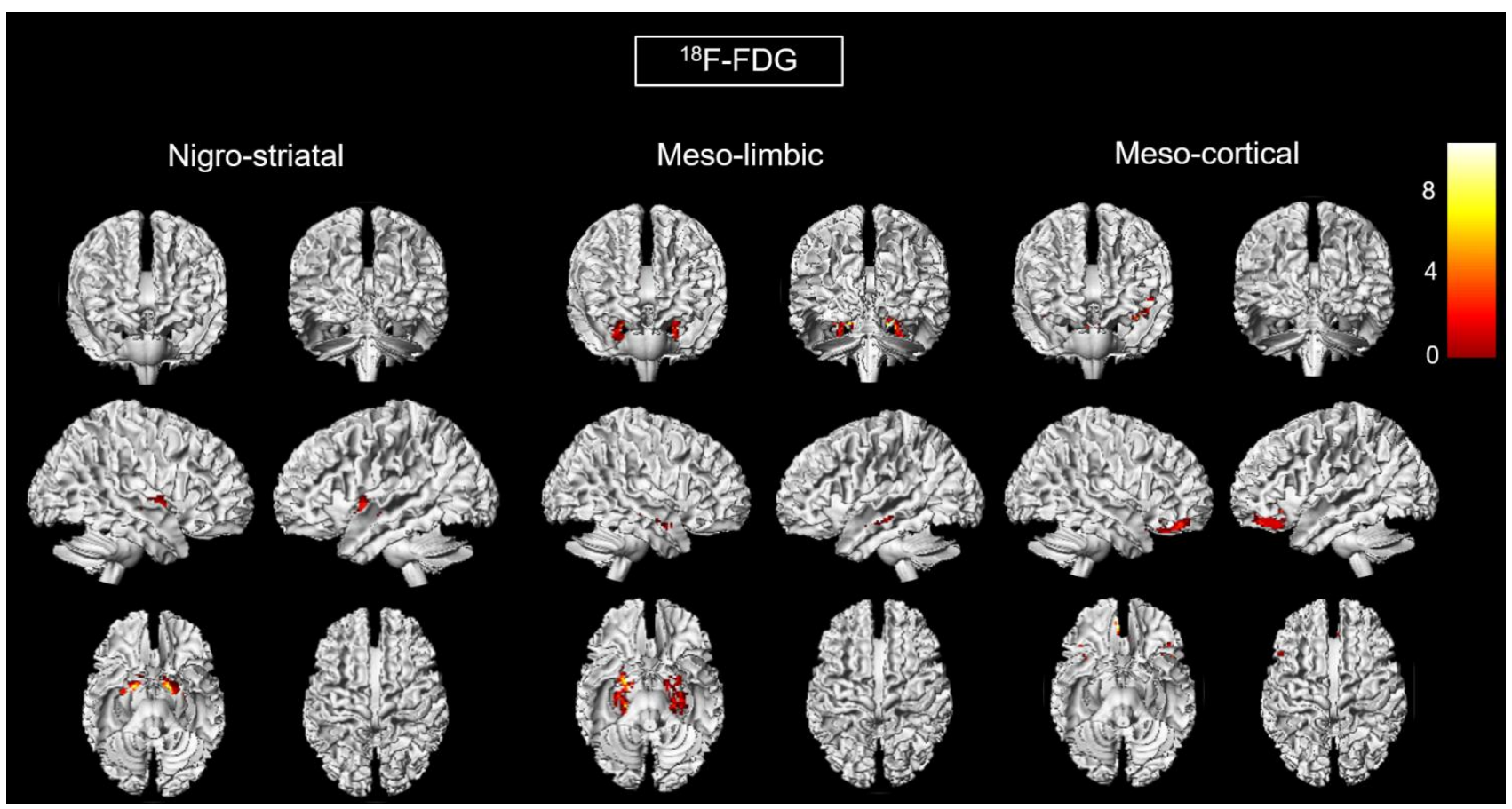


Figure 3. Anatomical localization of the 3 mesotelencephalic pathways identified by the ${ }^{123} \mathrm{I}-$ FP-CIT midbrain's connectivity analysis (T-voxel threshold of 2.80; $\mathrm{k}$ cluster size $>50$ voxels) projected onto 3D volume rendering, spatially normalized and smoothed into the standard SPM template

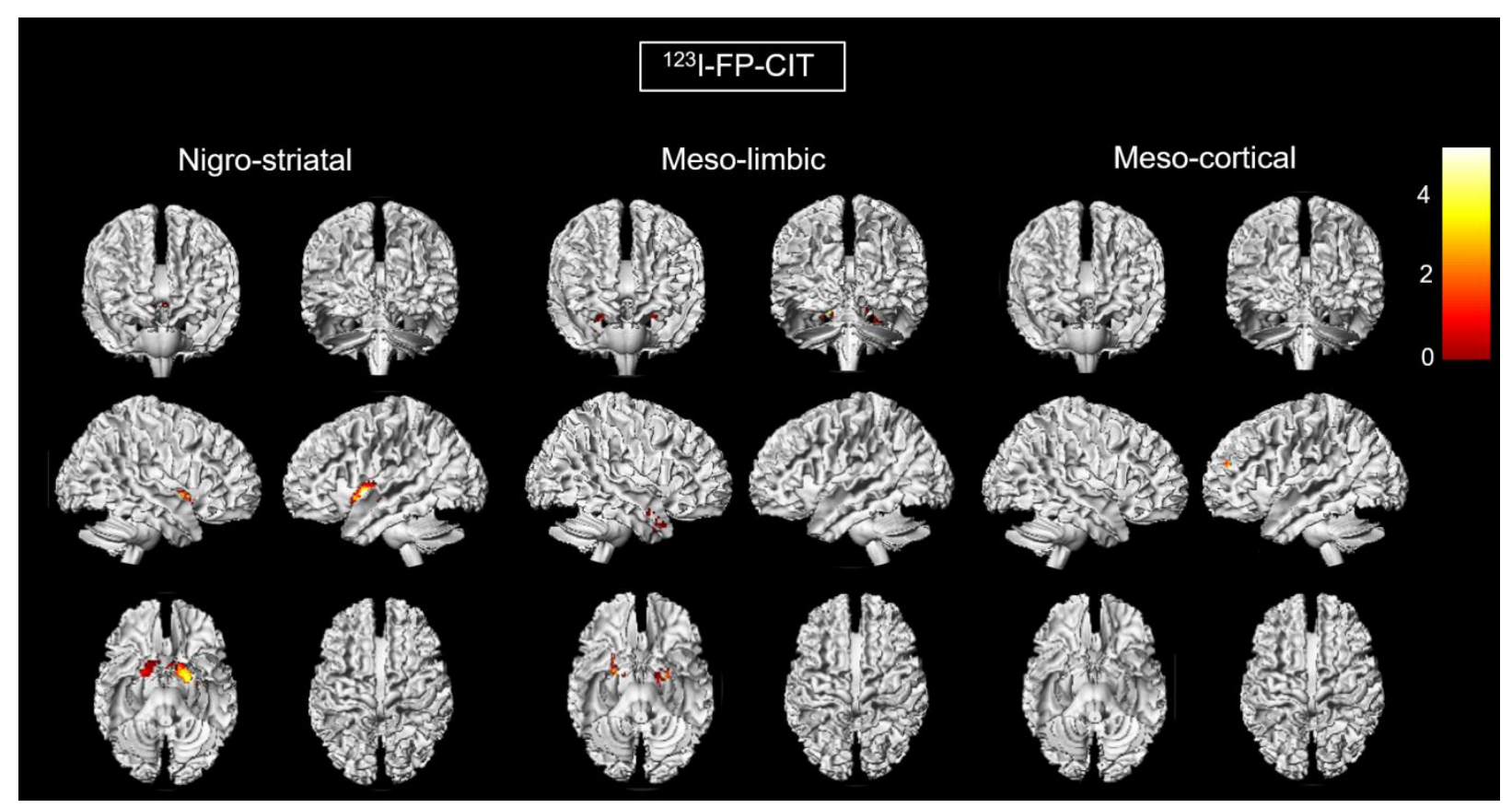


Figure 4. Anatomical localization of the 3 mesotelencephalic pathways identified by the ${ }^{18} \mathrm{~F}$ FDOPA midbrain's connectivity analysis (T-voxel threshold of 5.10; k cluster size >20 voxels) projected onto 3D volume rendering, spatially normalized and smoothed into the standard SPM template

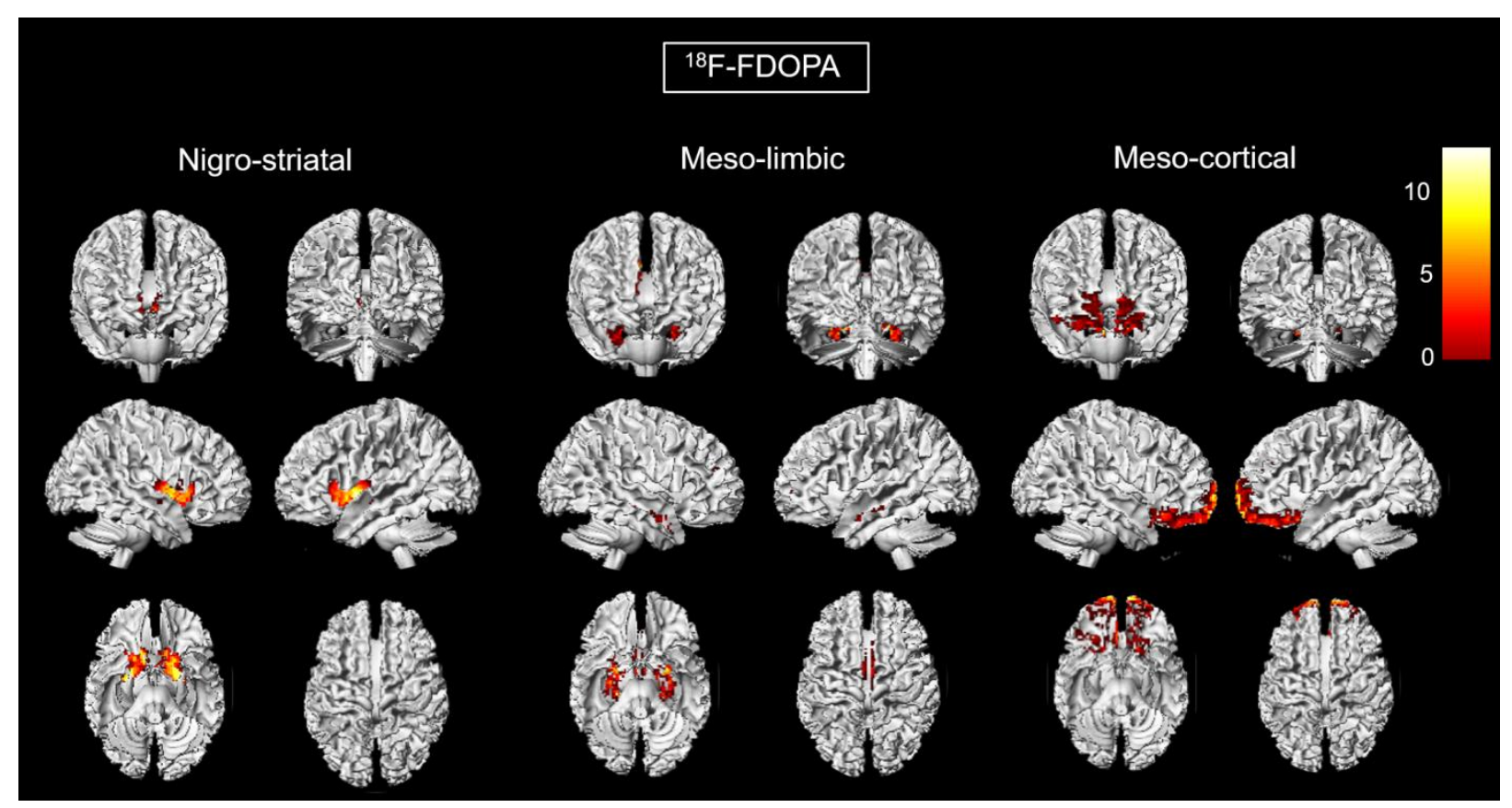


Figure 5. Significant findings of the midbrain's connectivity analysis found with ${ }^{18} \mathrm{~F}-\mathrm{FDOPA}$ PET and not with ${ }^{18}$ F-FDG PET (A) and found with ${ }^{18}$ F-FDG PET and not with ${ }^{18}$ F-FDOPA PET imaging (B), projected onto 3D volume rendering, spatially normalized and smoothed into the standard SPM template (T-voxel threshold value of 5.10; $\mathrm{k}$ cluster size $>20$ voxels)
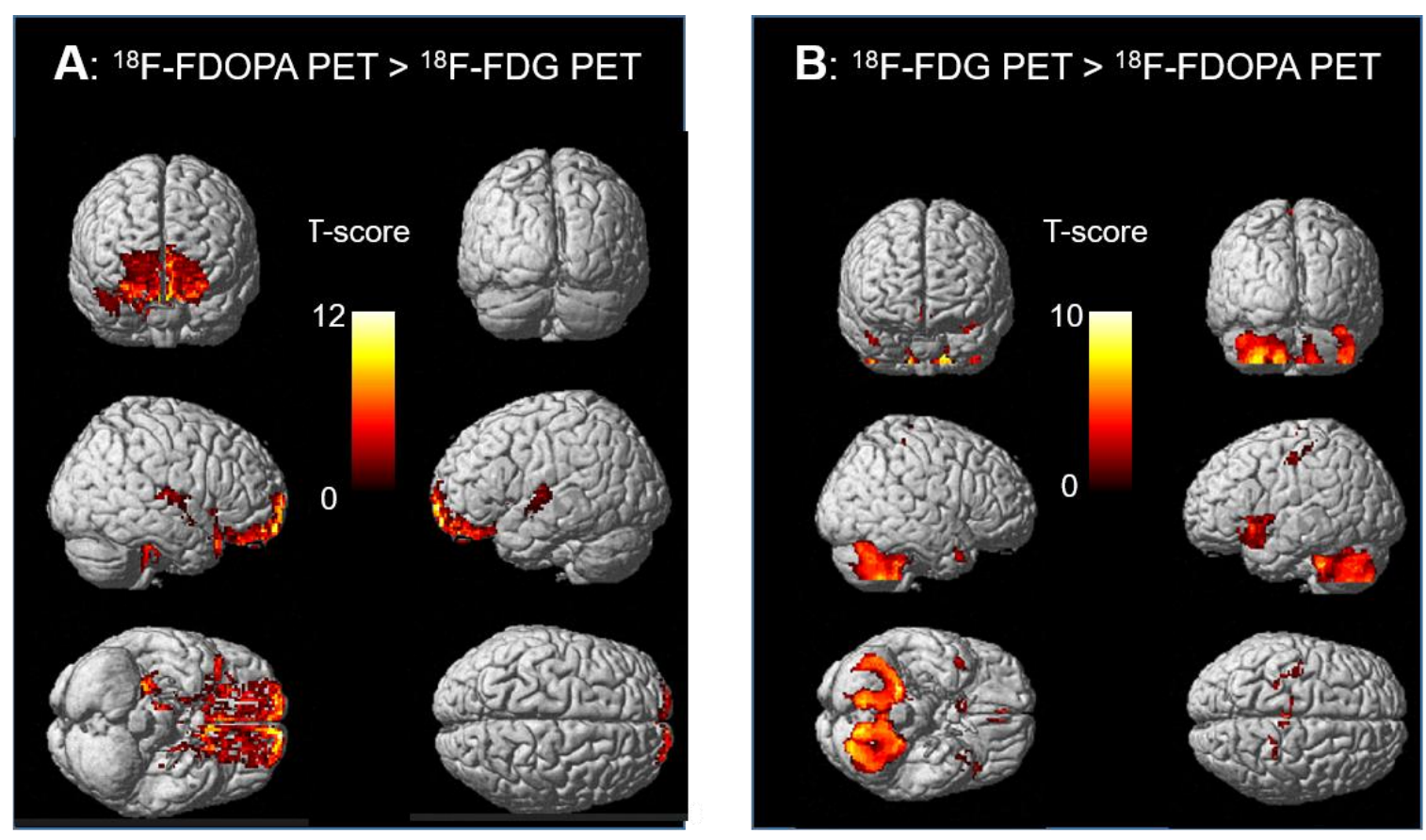